\title{
THE INFLUENCE OF ATRIAL SIZE AND ELASTICITY ON THE LEFT ATRIAL PRESSURE TRACING
}

\author{
BY \\ KENNETH F. FAIRLEY \\ From the National Heart Hospital* \\ Received November 8, 1960
}

There has been much argument for and against the value of the left atrial pressure tracing in the assessment of mitral stenosis and regurgitation Attention was first directed to the height and shape of the V wave (Lagerlöf and Werkö, 1949; Gorlin et al., 1952; Eliasch, 1952; Biorck et al., 1953; Logan and Turner, 1953; Connolly et al., 1955) and later to the diastolic y descent expressed as the $\mathrm{Ry} / \mathrm{V}$ ratio (Owen and Wood, 1955). While the use of the $\mathrm{y}$ descent generally provides a good guide to the type of mitral valve lesion present, an occasional case of dominant mitral regurgitation has a small $\mathrm{V}$ wave and an $\mathrm{Ry} / \mathrm{V}$ ratio within the stenotic range (less than $1 \cdot 7$ ).

The use of a pressure tracing to differentiate between mitral stenosis and regurgitation involves the assumption that a given change in the left atrial volume will, in different patients, result in the same change in left atrial pressure. However, two other factors beside the change in volume influence the pressure changes, namely the size of the left atrium and the elastic properties of its walls. An attempt has been made to assess the influence of these factors on the indirect left atrial pressure tracing and to review the value of the $\mathrm{Ry} / \mathrm{V}$ ratio in the light of these findings.

\section{Material AND Methods}

The $\mathrm{Ry} / \mathrm{V}$ ratio (Owen and Wood, 1955) was estimated in eighty patients in whom a clinical diagnosis of dominant mitral stenosis had been made. In the forty-seven who were proven subsequently, at autopsy (two) or operation (forty-five), to have pure mitral stenosis, a comparison is made between the $\mathrm{Ry} / \mathrm{V}$ ratio, atrial size, atrial elasticity, and the size of the mitral orifice. The eleven patients proven at operation to have varying degrees of mitral regurgitation are considered separately, and the remaining twenty-two, in whom all the relevant data were not available, were only used in Fig. 5 and in the assessment of the value of the Ry/V ratio.

Indirect left atrial tracings were obtained by wedging a cardiac catheter during inspiration in the lumen of a small branch of the pulmonary artery and recording the pressures by means of a Sanborn electromanometer employing hydraulic damping, with either a Polyviso direct-writing recorder or a photographic N.E.P. recorder. The criteria for a satisfactory wedged tracing were those of Owen and Wood (1955). The Fick method was used to determine the cardiac output, the sample of expired air being collected over an interval of five minutes. Oxygen saturation of the blood samples was estimated by the Haldane method.

Assuming the tense left atrium to be a sphere, an expression for atrial volume was calculated from the diameter of the left atrial outline on P.A. and oblique radiographs taken at six feet. That this method gives a satisfactory value for the comparison of left atrial size is shown in Fig. 6, where

* Present address:-Royal Melbourne Hospital, Australia. 
the relationship between increasing atrial size and atrial fibrillation is clearly shown. No allowance was made for the volume of the pulmonary veins since there is no readily available way of measuring this: the pulmonary veins in mitral stenosis tend to be constricted (Holling, 1951) and their volume is small in comparison with the volume of the distended left atrium.

The value used to express the elastic properties of the atrial wall combines the elastic modulus of the tissue of the atrial wall (E) and its thickness in centimetres (d), and can be estimated only in cases of "pure" mitral stenosis. In these cases the change of volume that causes the rise of pressure during the writing of the upstroke of the $\mathrm{V}$ wave can be calculated, if the cardiac output in litres per minute and the time between the mitral first sound and the opening snap is known. The assumption is made that, in these cases of mitral stenosis with raised left atrial pressures, there is no significant variation in flow from the pulmonary capillaries into the pulmonary venous system during the cardiac cycle. For example, if a patient with pure mitral stenosis had a cardiac output of 3.6 litres a minute $(60 \mathrm{ml} . / \mathrm{sec}$.) and the time that the mitral valve remained closed (i.e. the time between the mitral first sound and the opening snap) was found to be $0.3 \mathrm{sec}$. the increase in volume during systole would be $18 \mathrm{ml} .\left(\frac{3 \cdot 6 \times 1000}{60} \times 0.3=18 \mathrm{ml}\right.$. $)$

The rise of pressure that occurred during the time the mitral valve was closed $\left(P_{1}-P_{2}\right)($ Fig. 1) was measured from the lowest point of the $\mathrm{y}$ descent to the crest of the $\mathrm{V}$ wave.

Formula: Where $\mathrm{R}=$ the radius of the atrium,

$\delta R=$ the increase in the radius occurring in the time between the mitral first sound and the opening snap, and is small.

$P$ is $\left(P_{1}-P_{2}\right)$, the rise in pressure during the increase in radius (Fig. 1),

$\mathrm{E}$ is the elastic modulus of the atrial wall, and

$\mathrm{d}$ is the thickness of the atrial wall:

$$
\mathrm{Ed}=\frac{\mathrm{PR}^{2}}{4 \delta \mathrm{R}}
$$

If one considers two cases (Fig. 1) with atria of identical volume and elastic characteristics, and identical cycle flows, the slope of the y descent would be the same in each case and the left atrial pressure would be a measure of the degree of obstruction at the mitral valve, case A requiring a higher pressure to maintain the same mitral flow as B.

The $\mathrm{Ry} / \mathrm{V}$ ratio is the rate of the $\mathrm{y}$ descent divided by the height of the $\mathrm{V}$ wave. In Fig. 1, the $\mathrm{Ry} / \mathrm{V}$ ratio is $\frac{\mathrm{P}_{1} \mathrm{P}_{2}}{\mathrm{P}_{2} \mathrm{y}} \times \frac{1}{\mathrm{P}_{1} \mathrm{O}}$. Since the triangles $\mathrm{P}_{1} \mathrm{P}_{2} \mathrm{y}$ and $\mathrm{P}_{1} \mathrm{OZ}$ are similar, $\frac{\mathrm{P}_{1} \mathrm{P}_{2}}{\mathrm{P}_{2} \mathrm{Y}}=\frac{\mathrm{P}_{1} \mathrm{O}}{\mathrm{OZ}}$ and the $\mathrm{Ry} / \mathrm{V}$ ratio of $\mathrm{A}$ is therefore equal to $\frac{1}{\mathrm{OZ}}$ or the reciprocal of the time it would take for the left atrial pressure to fall to zero pressure if the y descent were continued as a straight line. This simple measurement avoids the usual calculations required when measuring the $R y / V$ ratio. Thus the $R y / V$ ratio of $A=\frac{1}{T_{A}}$ and of $B=\frac{1}{T_{B}}$. The orifice is larger in $B$ than $A$ and clearly $\frac{1}{T_{B}}$ is greater than $\frac{1}{T_{A}}$. Because of this reflection of the size of the orifice, the $R y / V$ ratio was chosen as an expression of the left atrial pressure tracing to compare with variations in volume and elastic characteristics of the atria, and the size of the mitral orifice.

Great care was taken when assessing the slope of the y descent to ensure that it was not influenced by respiratory pressure changes. All respiratory intrapleural pressure changes become superimposed on an indirect left atrial pressure tracing, and when these are large they may so dominate the tracing that a y "descent" actually rises during ventricular diastole as the intrapleural pressure rises during expiration (Fig. 2). Conversely the slope becomes much steeper during inspiration when the two falling pressures are summated. 


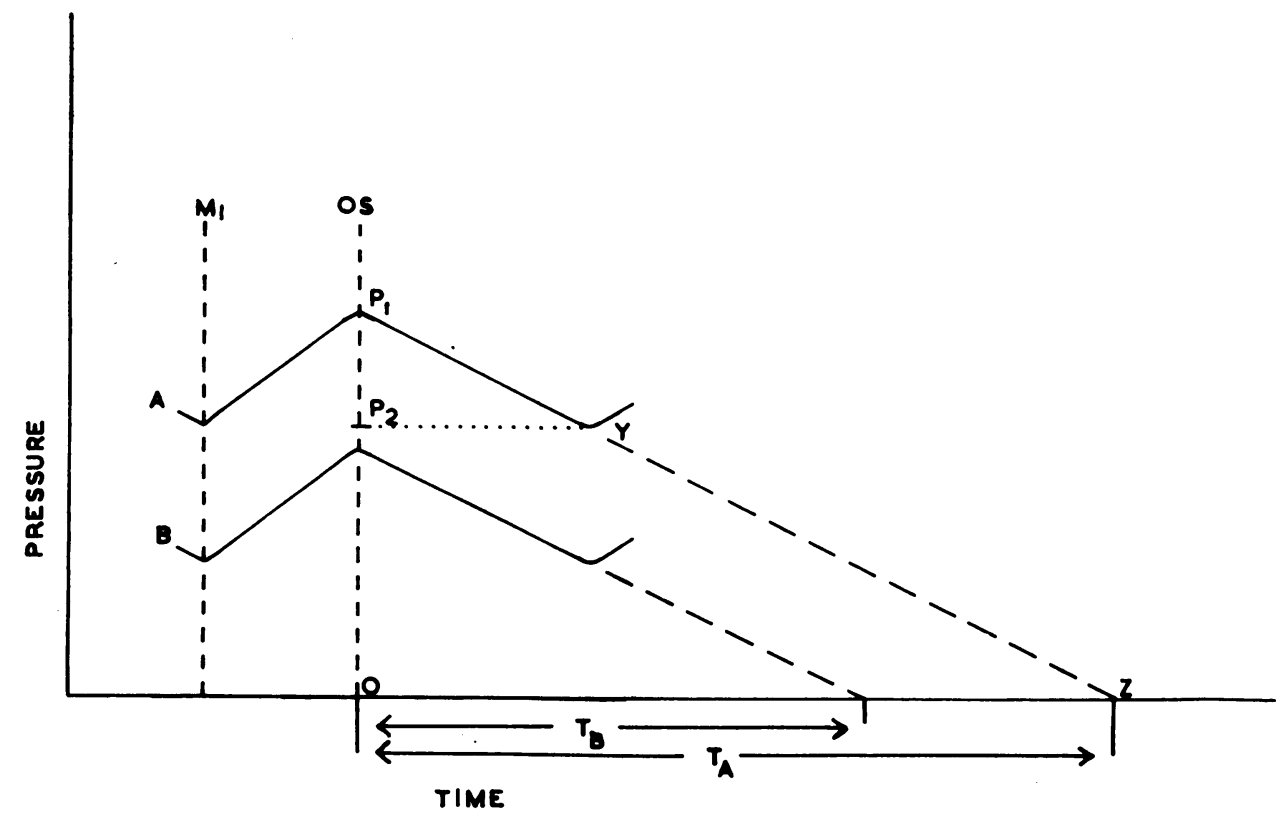

Fig. 1.-Diagrammatic representation of segments of left atrial pressure tracings from two hypothetical cases of mitral stenosis, $A$ and $B$, showing the upstroke of the $V$ wave and the $y$ descent. These cases are assumed to have the same volume and elastic characteristics and cycle flows, thus the difference in left atrial pressure reflects the smaller orifice size in A. The Figure demonstrates that the $R y / V$ ratio equals the reciprocal of the time taken for pressure to reach zero (i.e. $\frac{1}{T_{A}}$ and $\frac{1}{T_{B}}$ ). $M_{1}=$ Mitral first sound. $\quad$ OS=Opening snap.

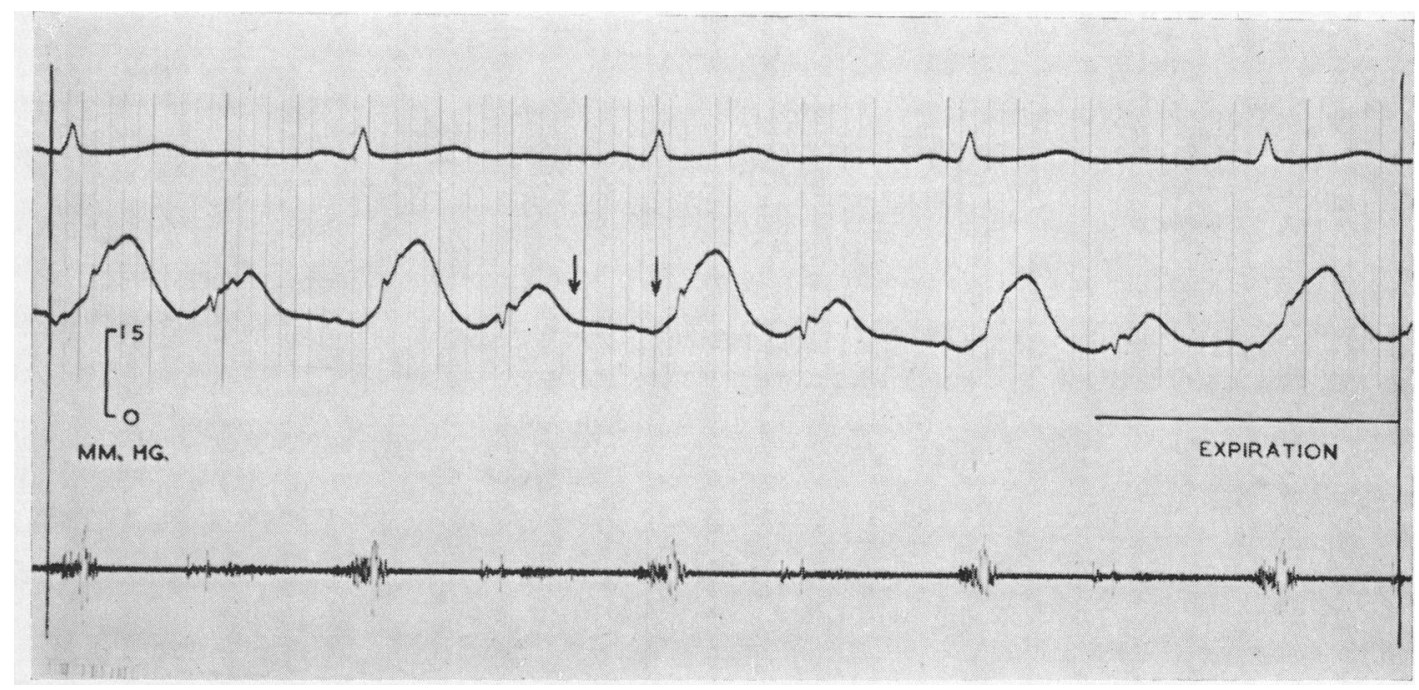

Fig. 2.-Simultaneous electrocardiogram, phonocardiogram, and wedged pulmonary arterial pressure tracing from a case of pure mitral stenosis $\left(0 \cdot 6 \mathrm{~cm} . .^{2}\right)$. The tracing shows the sharp fall in pressure sometimes seen immediately after $\mathrm{V}$, changing abruptly to a slower fall throughout the rest of the y descent (between arrows). For reasons given in the text the latter part of the y descent was used in measuring the Ry/V ratio. The Figure also shows the flattening of the y descent during expiration, due to the rise in intrapleural pressure. (Time markings $0.04 \mathrm{sec}$.) 
In some tracings, particularly when the atrium is small, there is an initial sharp fall in pressure following V, changing abruptly to a slower fall throughout the rest of the y descent (Fig. 2). That such an abrupt change in the slope of the y descent in mitral stenosis could be caused by an abrupt decrease in flow through the mitral orifice so early in diastole is inconceivable. The slope of the descent when the $\mathrm{Ry} / \mathrm{V}$ ratio was being measured was therefore taken from the later smoothly-falling pressure in mid-diastole. This early abrupt fall is not an artefact of the indirect left atrial tracing, for it is clearly seen in direct pressure tracings and commences as the left ventricular pressure falls below the left atrial pressure (Fig. 3). It probably represents a downward movement of the valve cusps, the reciprocal of the upward movement so often felt by the surgeon's finger during ventricular systole, and recorded in the operative record as "mobile cusps" (Fig. 3).
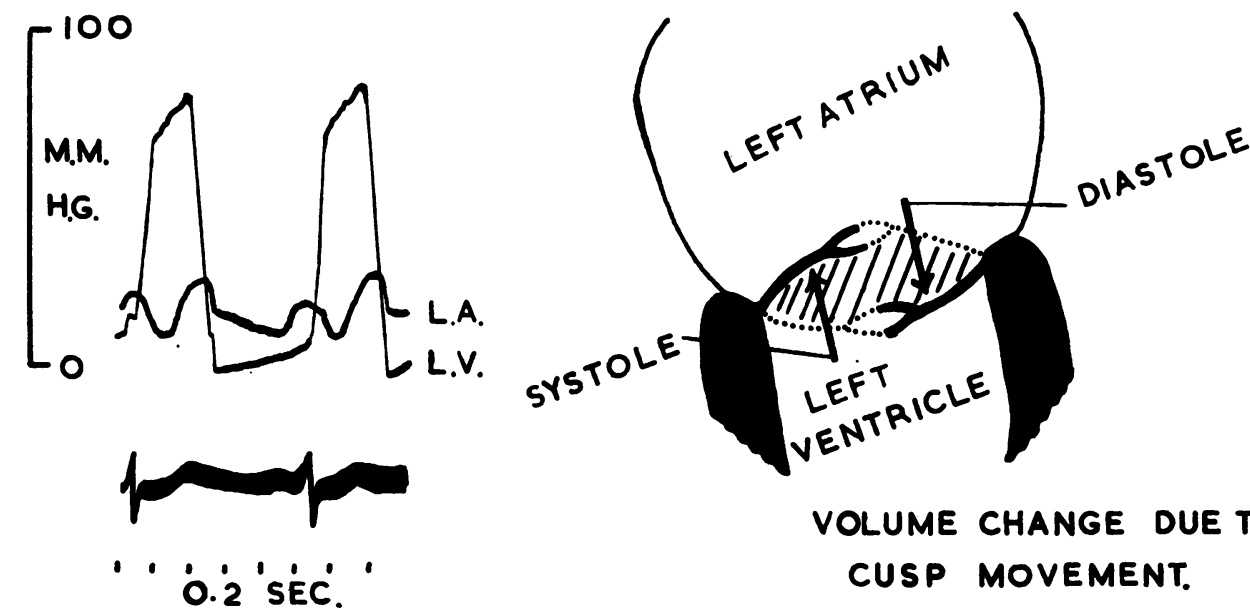

\section{VOLUME CHANGE DUE TO CUSP MOVEMENT.}

\section{SUPERIMPOSED DIRECT LEFT ATRIAL}

\section{\& VENTRICULAR PRESSURE} TRACINGS.

Fig. 3.-Showing that the early abrupt fall in the direct left atrial pressure tracing starts as the left ventricular pressure falls below left atrial pressure. For a short time the atrial pressure falls rapidly with the ventricular pressure. In the diagrammatic representation of cusp movement the shaded area represents the volume change in the left atrium that would allow such a rapid pressure change even in the presence of tight stenosis.

\section{RESULTS}

The cases have been divided into three groups according to the area of the mitral valve orifice (an arbitrary value obtained by multiplying the estimated length and breadth of the orifice; the relation to the true area of the orifice is unknown (Owen and Wood, 1955)). Group I comprises seventeen cases with a mitral orifice of less than $0.4 \mathrm{~cm} .^{2}$ in area (Fig. 4).; Group II, twenty-four cases with the area of this orifice varying between 0.4 and $0.95 \mathrm{~cm} . .^{2}$ (Fig. 5); and Group III, six cases with a mitral orifice of 1.25 to $1.50 \mathrm{~cm} . .^{2}$ in area (Table I).

From Fig. 4 and 5 it will be seen that the Ry/V ratio tends to be high when small or moderatesized atria are inelastic (a high Ed value). In large atria the increase in volume appears to play the dominant part and the $\mathrm{Ry} / \mathrm{V}$ ratio is low irrespective of the elasticity. When cases with a similar orifice size and atrial size are compared, the more inelastic the atrium (i.e. the higher the Ed value) the higher is the $\mathrm{Ry} / \mathrm{V}$ ratio. This explains why the correlation between the actual orifice size at operation and the $\mathrm{Ry} / \mathrm{V}$ ratio is poor in individual cases, when no account is taken of volume and elastic properties of the atrium. 
TABLE I

\begin{tabular}{c|c|c|c|c}
\hline Case & $\begin{array}{c}\text { Valve size } \\
\text { (sq. cm.) }\end{array}$ & $\begin{array}{c}\text { Atrial size } \\
\text { (diameter) }\end{array}$ & Ed value & Ry/V \\
\hline R.S. & 1.25 & $10 \mathrm{~cm}$. & 480 & 0.7 \\
A.T. & 1.5 & 11 & 1620 & 1.25 \\
K.Q. & 1.3 & 11.5 & 480 & 0.4 \\
J.S. & 1.5 & 11.5 & 370 & 1.5 \\
E.L. & 1.5 & 12 & 770 & 1.3 \\
C.B. & 1.5 & 14.5 & 3000 & 0.7 \\
\hline
\end{tabular}

It had been hoped that, when the $\mathrm{Ry} / \mathrm{V}$ ratio was assessed in the light of the atrial size and elastic properties of the atrium, an accurate prediction of the orifice size would be possible in an individual case. The results in the six cases with only mild stenosis (Table I) when plotted against the results in Fig. 5 do not support this. This may be due to insufficient accuracy in one or more of the measurements used.

In Fig. 5 there is an Ed value of 3300 which seems too high for an atrial diameter of $11.5 \mathrm{~cm}$. and an $\mathrm{Ry} / \mathrm{V}$ ratio of 1.4. This patient died of a pulmonary embolus whilst awaiting operation and at autopsy the upper half of the atrium was found to be filled with antemortem thrombus. This would have reduced the area of distensible atrial wall by about half, and if calculations are corrected accordingly, the Ed value falls to 1650 .

Two Ed values in Fig. 4 (1050 and 2290) do not conform to the usual pattern of a rising Ry/V ratio with rising Ed values. These two cases had several features in common. Both had an arterial

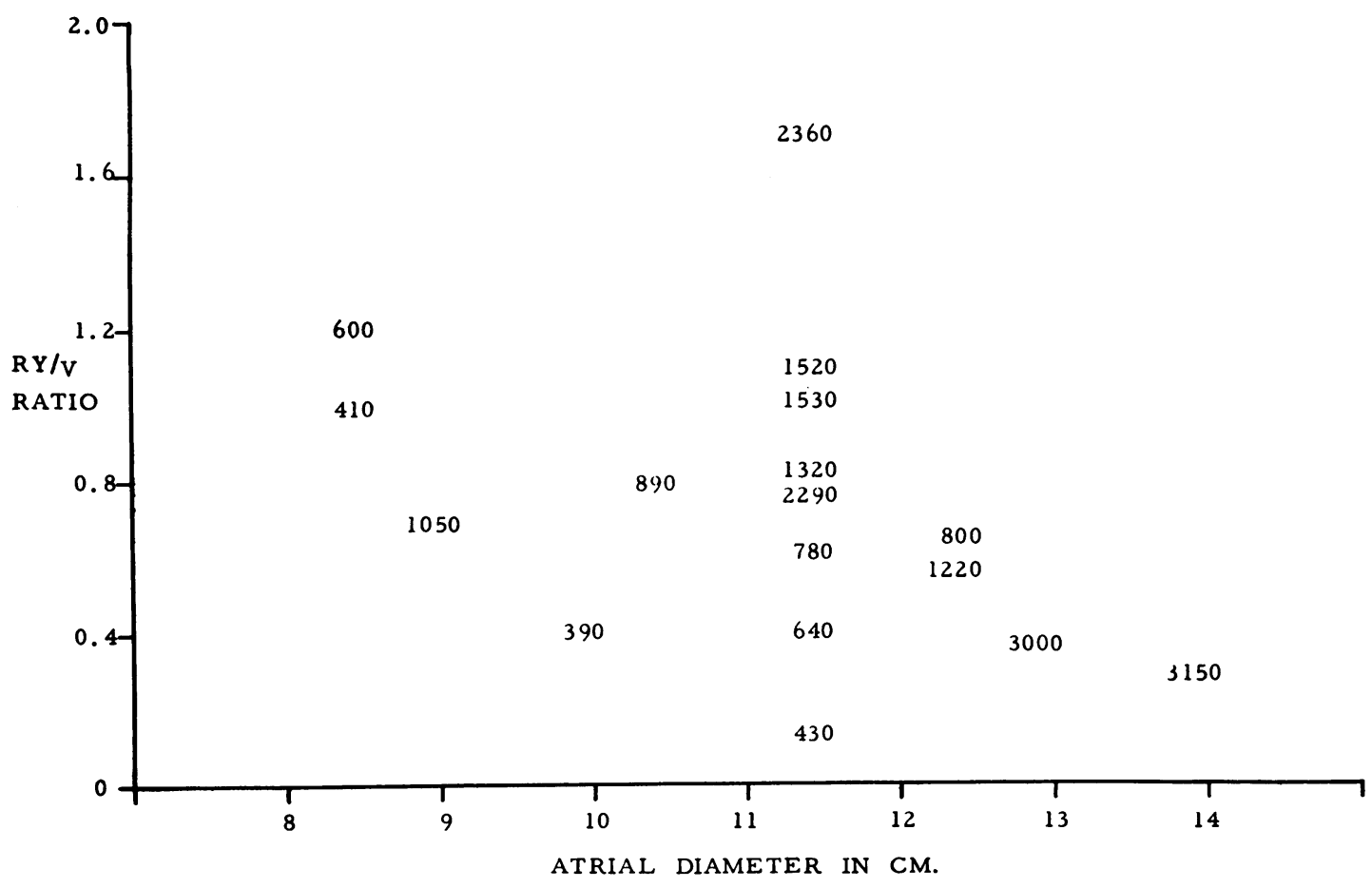

FIG. 4.-Seventeen cases of pure mitral stenosis with a mitral orifice area less than $0.4 \mathrm{~cm} . .^{2}$ The numerical values given are the calculated values for elasticity (Ed values) in each of the seventeen cases, and these are plotted in relation to the $\mathrm{Ry} / \mathrm{V}$ ratio and atrial size. The lower the numerical value, the more "elastic" the atrial wall. The Figure shows that in these cases with a comparable orifice size, the $R y / V$ ratio is influenced by the atrial size and by the elastic properties of the atrial wall. 


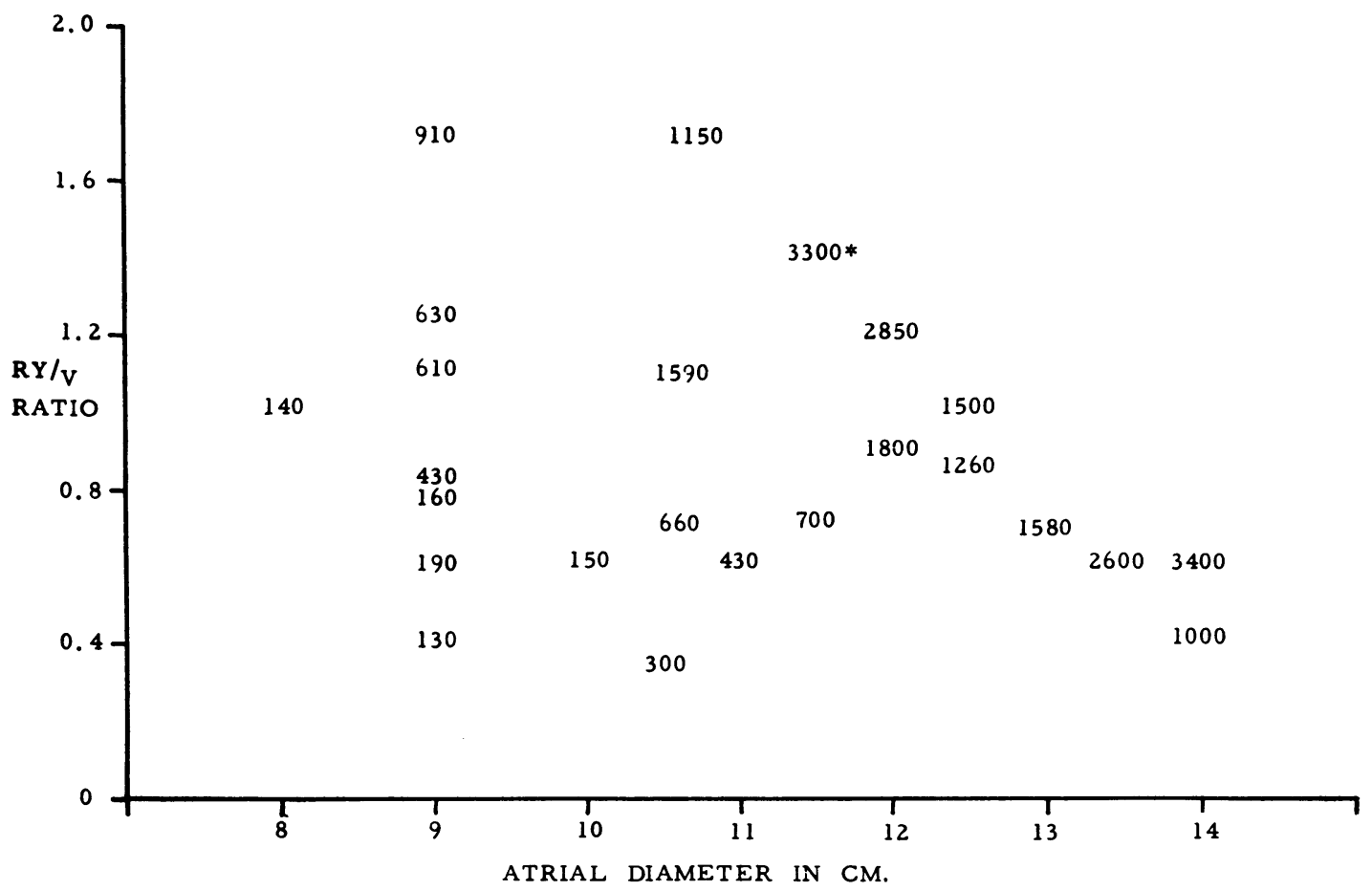

Fig. 5.-Twenty-four cases of pure mitral stenosis with a mitral orifice area between 0.4 and $0.95 \mathrm{~cm} .{ }^{2}$ The numerical values given are the calculated values for elasticity (Ed values) in each of the twenty-four cases, and these are plotted in relation to the $\mathrm{Ry} / \mathrm{V}$ ratio and atrial size. The lower the numerical value, the more "elastic" the atrial wall. The Figure shows that in these cases with a comparable orifice size, the Ry/V ratio is influenced by the atrial size and by the elastic properties of the atrial wall. The case marked by an asterisk (Ed 3300) is discussed in the text.

oxygen saturation of 80 per cent with a very low cardiac output $-1 \cdot 5$ and $1 \cdot 7$ litres a minute. The calculated volume entering the left atrium during the upstroke of the $\mathrm{V}$ wave, $9 \mathrm{ml}$. in each case, was the lowest in the whole series. Both had a very high mean left atrial pressure, 32 and $25 \mathrm{~mm} . \mathrm{Hg}$, and perhaps most important, an extreme pulmonary vascular resistance, 30 and 24 units respectively. In neither case was clot palpated by the surgeon in the atrial appendage.

The Ed values (Fig. 4 and 5) and the incidence of atrial fibrillation both increase with increasing atrial size, hence cases of fibrillation tend to have higher Ed values than those with sinus rhythm (Fig. 6). When the influence of the atrial size is eliminated by comparing atria of the same size $(10.5-11.5 \mathrm{~cm}$. in diameter) there is still a tendency for cases with atrial fibrillation to have less elastic atria (higher Ed values). No relationship was found between age and elasticity when atria of the same size were compared.

Variation in Elasticity in Mitral Regugitation. In eleven of eighty cases thought to have dominant mitral stenosis, some degree of mitral regurgitation had been diagnosed. At operation, five of these were found to have dominant mitral regurgitation. In only one was the Ry/V ratio above 1.7; however, as the Ry/V ratio has been shown to fall with increasing atrial size (Fig. 4 and 5), the value of 0.7 in one case with a giant left atrium $(19 \mathrm{~cm}$. in diameter) is also suggestive of mitral regurgitation.

When the Ed value was calculated in these eleven cases as if there was no mitral regurgitation, values within the mitral stenotic range for the atrial size concerned were found in all but four of them. Since three of the patients with values within the stenotic range were known to have dominant mitral regurgitation, the true Ed value must have been very much less, implying that large variations in 
elasticity also occur in mitral regurgitation. The $\delta R$ used in these calculations is much smaller than the one that would result from both regurgitant and forward flow.

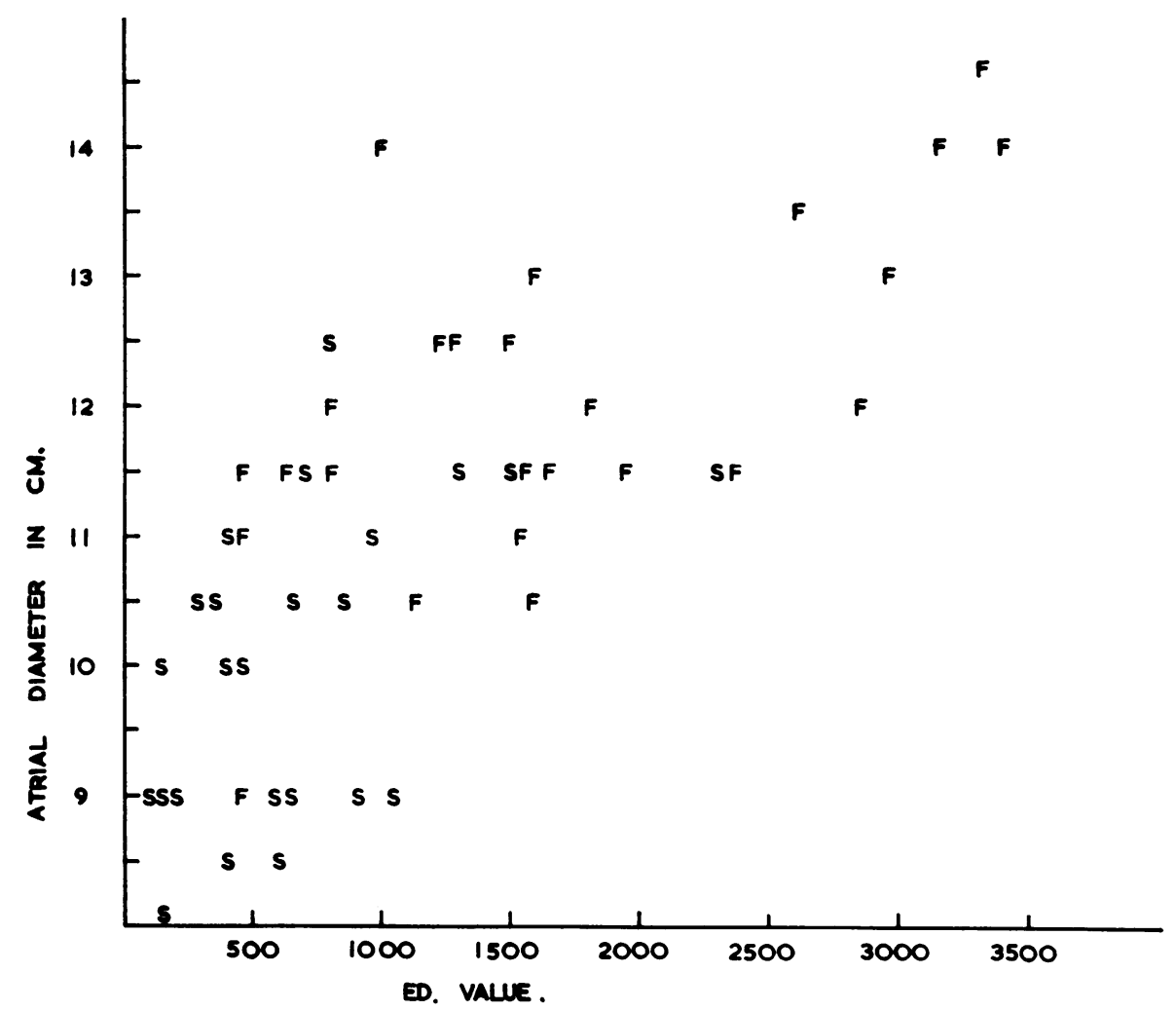

FIG. 6.-Forty-nine cases of mitral stenosis in which the rhythm is denoted by the letters $\mathbf{S}$ (sinus rhythm) and F (atrial fibrillation). The atrial size in these cases is plotted against the calculated elasticity (Ed) value. The relationship between increasing atrial size and incidence of atrial fibrillation is clearly seen. There is also a tendency for cases with atrial fibrillation to have less elastic (higher Ed value) atria than those in sinus rhythm, and this is still apparent when the influence of atrial size is eliminated by comparing atria with a diameter of 10.5 to $11.5 \mathrm{~cm}$.

\section{Discussion}

The difficulties in assessing the severity and type of mitral valvular lesions are well known, and additional help has often been sought from the left atrial pressure tracing. When attempts are made to interpret such pressure changes in terms of volume changes, variations in the elastic characteristics of the left atrium and pulmonary veins are of great importance. Because of the difficulties in measuring the pulmonary venous volume and the fact that the veins are usually constricted in cases of mitral stenosis (Holling, 1951), only the volume of the left atrium was considered in calculating an expression for the elastic properties of the system.

Calculations to estimate the variations in the elastic properties show that as the atrial size increases, the Ed value also rises, (i.e. the wall becomes less elastic. If a given volume change were to produce the same pressure change in three atria of $8.5,14$ and $19 \mathrm{~cm}$. diameter, the largest would have to be twenty-five times and the middle-sized one five times as inelastic as the smallest atrium (where $E d=\frac{P R^{2}}{4 \delta R}$ is taken as a measure of elasticity). Considerable variation in elasticity was also demon- 
strated between atria of the same estimated size with a comparable degree of mitral stenosis, and in one group variations were as great as seven to one. Such changes greatly modified the form of the indirect left atrial tracing and therefore the $\mathrm{Ry} / \mathrm{V}$ ratio and size of the $\mathrm{V}$ wave.

In the eleven cases with regurgitation, the Ed value was calculated as if forward flow alone had produced the recorded pressure rise. The anticipated high values were found in only four cases, the remaining seven having values within the range of the pure stenotic group. Since the error is proportional to the ratio of forward to regurgitant flow volumes, this error would have been considerable in the three patients proven at operation to have dominant mitral regurgitation and hence the walls of these atria must have been very elastic. In such cases the $\mathrm{V}$ wave is small, the y descent gradual, and the $\mathrm{Ry} / \mathrm{V}$ ratio low, because these moderate to large-sized atria distend readily, and a comparatively small pressure rise accompanies the large volume increase as they fill simultaneously from the pulmonary veins and left ventricle.

A very much higher Ed value than that expected for a particular $\mathrm{Ry} / \mathrm{V}$ ratio and atrial size should arouse a suspicion of considerable mitral regurgitation. For example, one patient with an atrium $12 \mathrm{~cm}$. in diameter and an $\mathrm{Ry} / \mathrm{V}$ ratio of $0 \cdot 7$, had an Ed value (estimated without correction for regurgitant flow) of 10,000. Another possible source of error in deriving the Ed value is that the output, though measured during the same cardiac catheterization, may not be the same as the output when the indirect left atrial tracing was recorded. The presence of thrombus or calcification, which renders an area of atrial wall comparatively indistensible, has the effect of reducing the atrial volume which should be used in the calculations by an amount equal to the volume enclosed by this inelastic segment. This would give an artificially high Ed value. A large thrombus, provided it were attached to only a small area of atrial wall, would have no such effect.

The Ry/V ratio did not exceed 1.7 in seventy-six cases of mitral stenosis, and when high occurred in small or moderate-sized atria with relatively inelastic walls (high Ed values). A high $\mathrm{Ry} / \mathrm{V}$ value is thus useful in excluding significant stenosis, particularly if the Ed value is low or the atrium very large. Care must be taken when measuring the $\mathrm{Ry} / \mathrm{V}$ ratio to avoid super-added respiratory pressure changes and the type of "artefact" shown in Fig. 2.

The use of direct left atrial tracings with a simultaneous accurate dye output would increase the reliability of individual observations.

\section{SUMMARY}

Considerable variations in atrial size and the elastic characteristics of the atrial wall were demonstrated in cases with a comparable degree of mitral stenosis.

Both these factors greatly modify the form of the indirect left atrial tracing. The $\mathrm{Ry} / \mathrm{V}$ ratio is used as a numerical expression of this to compare with the variations in volume and elasticity. A simplified method of measuring the $\mathrm{Ry} / \mathrm{V}$ ratio is suggested.

Evidence is presented that similar if not greater variations in elasticity are present in cases of mitral regurgitation. When an enlarged atrium is easily distensible, the typical high $\mathrm{V}$ wave and high $\mathrm{Ry} / \mathrm{V}$ ratio are absent and the tracing is indistinguishable on these criteria from those found in mitral stenosis. Four cases with an $\mathrm{Ry} / \mathrm{V}$ ratio of less than 1.7 were found to have dominant mitral regurgitation.

In no case of mitral stenosis, when errors in measuring the $\mathrm{Ry} / \mathrm{V}$ ratio were avoided, did the $\mathrm{Ry} / \mathrm{V}$ ratio exceed $1 \cdot 7$. Values tend to be high in small to moderate-sized atria which are comparatively inelastic, while much lower values are the rule in large-sized atria.

An elevated $\mathrm{Ry} / \mathrm{V}$ ratio is considered to be good evidence against the presence of significant mitral stenosis, and the larger the atrium the stronger is this evidence.

I am grateful to Dr. Paul Wood for access to his case records and for his advice and encouragement, and to Dr. Allan Townsend of Emmanuel College, Cambridge, for the derivation of the mathematical formula used. 


\section{REFERENCES}

Biorck, G., Axen, O., Krook, H., Andren, L., and Wulff, H. B. (1953). Amer. Heart J., 45, 13.

Connolly, D. C., Burchell, H. B., Kirklin, J. W., and Wood, E. H. (1955). Fed. Proc., 14, 30.

Eliasch, H. (1952). Scand. J. clin. Lab. Invest. Suppl., 4, 1.

Gorlin, R., Lewis, B. M., Haynes, F. W., and Dexter, L. (1952). Amer. Heart J., 43, 357.

Holling, H. E. (1951). Guy's Hosp. Gaz., 65, 271.

Lagerlöf, H., and Werkö, L. (1949). Scnad. J. clin. Lab. Invest., 13, 147.

Logan, A., and Turner, R. (1953). Lancet, 1, 1007.

Owen, S. G., and Wood, P. (1955). Brit. Heart J., 17, 41. 